\title{
Non-invasive prenatal testing for single gene disorders: exploring the ethics
}

\author{
Zuzana Deans ${ }^{1}$, Melissa Hill ${ }^{2}$, Lyn S Chitty ${ }^{2}$ and Celine Lewis ${ }^{\star, 3}$
}

Non-invasive prenatal testing for single gene disorders is now clearly on the horizon. This new technology offers obvious clinical benefits such as safe testing early in pregnancy. Before widespread implementation, it is important to consider the possible ethical implications. Four hypothetical scenarios are presented that highlight how ethical ideals of respect for autonomy, privacy and fairness may come into play when offering non-invasive prenatal testing for single gene disorders. The first scenario illustrates the moral case for using these tests for 'information only', identifying a potential conflict between larger numbers of women seeking the benefits of the test and the wider social impact of funding tests that do not offer immediate clinical benefit. The second scenario shows how the simplicity and safety of non-invasive prenatal testing could lead to more autonomous decision-making and, conversely, how this could also lead to increased pressure on women to take up testing. In the third scenario we show how, unless strong safeguards are put in place, offering non-invasive prenatal testing could be subject to routinisation with informed consent undermined and that woman who are newly diagnosed as carriers may be particularly vulnerable. The final scenario introduces the possibility of a conflict of the moral rights of a woman and her partner through testing for single gene disorders. This analysis informs our understanding of the potential impacts of non-invasive prenatal testing for single gene disorders on clinical practice and has implications for future policy and guidelines for prenatal care. European Journal of Human Genetics (2013) 21, 713-718; doi:10.1038/ejhg.2012.250; published online 28 November 2012

Keywords: non-invasive prenatal diagnosis; cell-free fetal DNA; single gene disorders; ethics

\section{INTRODUCTION}

The technology underpinning the development of non-invasive prenatal testing (NIPT) based on cell-free fetal DNA (cffDNA) is advancing rapidly and the promise of accurately detecting aneuploidies and genetic conditions early in pregnancy using a maternal blood test is now being realised. The clinical benefit of NIPT is clear as the risk of miscarriage that accompanies current invasive methods of prenatal diagnosis will be avoided. It is important, however, to pause and consider the wider implications of offering these tests. The implementation of NIPT should not be solely dependent on the availability of the technology; stakeholder views are critical and the tests must be ethically justifiable. Although many of the ethical issues that have been raised about NIPT are not new to prenatal diagnosis, the practical and potentially moral 'advantages' of NIPT, resulting from no risk of miscarriage and potentially earlier testing, do alter the choices presented to women and families, and to policymakers. As a result, there is a corresponding change to the moral nature of prenatal diagnosis and screening programmes.

Several commentators have drawn attention to the potential shift in the balance of ethical principles brought about by the implementation of NIPT. ${ }^{1-4}$ The issues raised include: the potential to undermine informed consent as women may not to give sufficient consideration to testing as NIPT is 'just another blood test'; the risk of normalising testing as routine, which again can negatively impact on informed consent; increased societal pressure to take up testing and to terminate an affected pregnancy; and misuse of NIPT to test for minor reasons. ${ }^{1-4}$ These concerns have also come to the fore in studies looking at stakeholder views of NIPT. ${ }^{5-8}$ Much of the discussion to date has focused on the application of NIPT within programmes for Down's syndrome screening and diagnosis. In this paper, we aim to show how general concerns about NIPT apply to testing for single gene disorders and highlight how some of the ethical considerations will relate specifically to this area of practice. To do this, we use four hypothetical cases studies to demonstrate how ethical ideals of respect for autonomy, privacy and fairness could potentially be adhered to or compromised.

\section{PRENATAL DIAGNOSIS OF SINGLE GENE DISORDERS}

Prenatal diagnosis is an option available to many couples with pregnancies at risk of single gene disorders and upward of 1500 prenatal tests for over 100 different genetic conditions are performed each year in the United Kingdom. ${ }^{9}$ In many cases, the prospective parents will already be aware that the pregnancy is at risk of a genetic condition as their own carrier status will have been established before conception. This may be the result of cascade testing when there is a family history of the condition; a previous child identified with a condition through newborn screening or symptoms detected in childhood; or, less frequently, preconception carrier screening programmes for conditions such as Tay-Sachs, cystic fibrosis or fragile X-syndrome. ${ }^{10}$ For other parents, carrier status can come to light during pregnancy if a family history of a condition is newly established or through a prenatal carrier screening programme, such as haemoglobinopathy screening. ${ }^{11}$ It is also possible that ultrasound

${ }^{1}$ Department of Community Based Medicine, Centre for Ethics in Medicine, University of Bristol, Bristol, UK; ${ }^{2}$ Clinical and Molecular Genetics, Institute of Child Health and Great Ormond Street Hospital for Children NHS Foundation Trust, London, UK; ${ }^{3}$ Genetic Alliance UK, London, UK

*Correspondence: Dr C Lewis, Genetic Alliance UK, Unit 4D Leroy House, 436 Essex Road, London N1 3QP, UK. Tel: + 44 (0)20 77043141 ; Fax: + 44 (0)20 73591447 ; E-mail: celine@geneticalliance.org.uk

Received 6 August 2012; revised 26 September 2012; accepted 28 September 2012; published online 28 November 2012 
findings will indicate that a new mutation has arisen de novo for an autosomal dominant condition such as achondroplasia. ${ }^{12}$

Prenatal diagnosis of single gene disorders has traditionally been dependent on the use of invasive diagnostic tests (chorionic villus sampling and amniocentesis), which carry a risk of miscarriage of around $1 \%{ }^{13}$ and can only be safely conducted after 11 weeks gestation. NIPT based on cffDNA present in the maternal plasma will allow women to have prenatal diagnosis using a blood test. The cffDNA is pregnancy specific as it is cleared from the circulation within 30 min of delivery ${ }^{14,15}$ and can be detected from 5 weeks in pregnancy, ${ }^{16}$ so that NIPT for single gene disorders could be feasible from early in pregnancy, although data indicate that it is not reliable until after 7-9 weeks. ${ }^{17}$ Consequently, NIPT brings the possibility of both safer and earlier testing for couples at risk of single gene disorders.

Only a small proportion (around 10\%) of the cell-free DNA that is present in the maternal circulation comes from the fetus and the vast majority is maternal in origin. ${ }^{18}$ This relatively low level of free fetal DNA has been a major barrier to the development of NIPT as it is difficult to determine what genetic information is specific to the fetus against the large background of maternal cell-free DNA. For this reason, the first clinical uses of NIPT have been limited to the identification of gene changes present in the fetus but not in the mother, because they were inherited from the father or because they arose as a result of a de novo mutation. Accordingly, one of the early successes of NIPT in clinical practice has been fetal sex determination for women at risk of having a child with a genetic condition that primarily affects a particular sex, which is based on detecting the presence or absence of $\mathrm{Y}$ chromosome-specific sequences in the maternal plasma. ${ }^{19}$ NIPT for fetal sex determination is viewed positively by women who have had the test ${ }^{20,21}$ and has been show to be cost neutral. ${ }^{22}$

The development of NIPT tests for single gene disorders is ongoing. NIPT has been used to diagnose several autosomal dominant conditions that are paternally inherited or have arisen de novo, ${ }^{23}$ including, torsion dystonia ${ }^{24}$ and achondroplasia. ${ }^{12}$ In addition, NIPT has been used for excluding a paternal mutation in autosomal recessive conditions when parents carry different mutations, such as beta thalassaemia. ${ }^{25}$ The advent of new technologies such as next-generation sequencing and digital PCR is expanding this outlook and proof-of-principle studies have clearly demonstrated that NIPT can be successfully applied to X-linked conditions ${ }^{26}$ and recessive conditions where parents carry the same mutation. $^{27-29}$

\section{EXPLORATION OF ETHICAL ISSUES}

In this paper, we assume that prenatal testing in general is ethically acceptable, and look in detail at four hypothetical scenarios in which using NIPT to diagnose single gene disorders might impact upon ethical aspects of clinical practice. At present, NIPT is only available clinically for the diagnosis of a very limited number of single gene disorders. For each of the scenarios described here, we are assuming that the NIPT test is available, that it can be performed from 7 weeks gestation and that the accuracy is the same as for invasive testing (>99\%).

Hypothetical scenario 1: a couple who wants to plan and prepare Anne and David are expecting their second child. Their first child has cystic fibrosis (CF), and they are therefore aware that they are both carriers of the condition. Anne and David agree that they would not terminate an affected fetus, but have asked their genetic counsellor whether they can have NIPT to prepare during pregnancy.

$\mathrm{CF}$ is an autosomal recessive condition caused by mutations in the CFTR gene. CFTR is important for the movement of salt and water in and out of cells and people affected by CF have a build up of sticky mucus, particularly in their lungs and digestive system. There is no cure for CF; however, treatments have improved dramatically in recent years and life expectancy is now above 40 years.

For Anne and David, undergoing NIPT allows earlier diagnosis, without the risk of miscarriage and the associated anxiety, and without the physical discomfort of the invasive testing procedure. ${ }^{30}$ Depending on the result, NIPT will provide Anne and David with either early reassurance if the pregnancy is unaffected or time and space for preparation if the pregnancy is affected. Similarly, the utility of having early knowledge about the pregnancy would also apply to those women who know they are at risk but do not already have an affected child.

Research asking service users' views about NIPT for fetal sex determination have shown that early reassurance is a welcome aspect of NIPT, and that finding out the fetus is at low risk brings 'peace of mind' and helps prospective parents enjoy a 'normal' pregnancy earlier than would be possible with traditional invasive testing pathways. ${ }^{20}$ Conversely, if the fetus is affected Anne and David can start to prepare mentally and practically for raising a child with CF. Although this result is not what the couple would hope for, having a definitive answer early in pregnancy may imbue Anne and David with a sense of control and autonomy over their pregnancy as well as providing early relief from uncertainty. These are key attributes identified as patient-desired outcomes of genetic counselling ${ }^{31-33}$ that have been reported by women having NIPT for fetal sex determination. ${ }^{20}$

Provided Anne and David are equipped (with the aid of genetic counselling) for both possible outcomes of the test, and provided they undergo the test through their own choosing, the provision of a diagnosis through NIPT is a wholly positive advancement. However, Anne and David's particular situation is not insulated from wider ethical questions; assessing the advantages and disadvantages of using NIPT for information is only part of the picture. Any moral argument for implementing NIPT for testing for 'information only' (with no intention to terminate) in a state-funded healthcare system would have to include justification for directing limited national health resources towards this use when it will not change pregnancy management. This is particularly pertinent here, as women often feel ambivalent towards invasive testing due to the conflict between a desire for information and the risk of miscarriage. ${ }^{34}$ The availability of NIPT and the possibility of genetic diagnosis with no risk of miscarriage may thus result in larger numbers of couples taking up testing for information only.

Looking to the future where genome-wide sequencing promises to allow the diagnosis of multiple genetic conditions with a single noninvasive test, ${ }^{29,35}$ it is possible that a panel of tests for common conditions could be offered to parents not already identified as carriers of a particular single gene disorder. In this setting, there may be many parents who will want the reassurance of having prenatal screening, but say that they would not choose to have a termination of pregnancy if the fetus is affected. As these tests could be offered to all pregnant women, the result could be a significant increase in the numbers of people seeking testing for single gene disorders, raising yet further questions about how to fund tests that would have no immediate clinical benefit. Furthermore, questions such as whether 
women should be allowed to access testing 'for information only' through private providers and the subsequent reduction in equity of access that would result also needs to be considered.

The issues that arise in any discussion of testing for information only will differ depending on the nature of the single gene disorder in question. For example, with $\mathrm{CF}$, if the parents are seeking testing without the intention to terminate, then there is no clear clinical benefit of knowing if the fetus is affected before birth. For a condition such as haemophilia, either genetic diagnosis or knowledge of fetal sex is critical to guide management of labour and delivery of males 'at risk' of haemophilia. The use of NIPT for fetal sex determination for haemophilia has raised debate around the acceptability of offering tests in a state-funded healthcare system when the immediate clinical benefit of the test is unclear. Using NIPT to determine fetal sex, when this could be carried out via routine ultrasound at no extra cost later in pregnancy, has resulted in some clinical services in the UK only offering NIPT when it will change pregnancy management as they consider the additional cost is not balanced by clinical benefit. ${ }^{36}$ Indeed, in the UK, the regulatory body (the UK Genetic Testing Network) has not approved fetal sex determination using NIPT in pregnancies at risk of haemophilia for this reason. However, others have argued that to meet patient need, it is important to take into account the wider variety of benefits associated with NIPT for carriers of haemophilia as they have described a number of psychological advantages of early testing. ${ }^{20}$ Consequently, it is important that policymakers consider how we measure the psychological benefits of testing alongside clinical utility and weigh up whether the nonclinical personal benefits justify the cost of the test.

Denying NIPT to those testing for information only would in many cases involve differentiating between those who know in advance they would consider terminating an affected pregnancy and those who know in advance they would not. Given that decision-making about prenatal testing and termination is not straightforward, and women do not always know how they will respond to the results until they are given $^{20}$ the assumption that women could reliably predict their decisions in advance of receiving information seems flawed. Further, even if there was sound justification for measuring costeffectiveness purely in terms of clinical outcome, or for prioritising the benefits of decisions about continuing or terminating a pregnancy over the benefits of being prepared, policymakers should consider that making such a distinction might imply that NIPT was a resource for informing decisions about termination, rather than providing women with information about their pregnancies per se.

Whether NIPT would be used more widely for information only will depend on at least three ethical considerations: (i) whether the non-clinical outcomes are regarded as benefits when measuring costeffectiveness; (ii) whether it is deemed acceptable to offer NIPT only to those women who declare they would consider termination on the basis of the results; and (iii) whether there are ever circumstances in which NIPT can be offered for information only when there is no clinical benefit.

\section{Hypothetical scenario 2: a woman who changes her mind}

Katie has a 2-year-old daughter and is now pregnant with her second child. Katie's father has Becker muscular dystrophy (BMD) and she knows she is a carrier of the condition. Katie feels quite certain that she would be able to raise a child with BMD and would not terminate an affected fetus. When she was pregnant with her first child, Katie did not have prenatal testing because she did not want to put the pregnancy at risk and did not want to put herself in a position where she would have to make a decision about termination.
When Katie speaks to her genetic counsellor she learns that NIPT is now available to diagnose BMD. Even though she initially did not want to take the test, she finds it difficult to decline as this new technology is just a blood test and freely available. Ultimately, she decides she 'might as well' take the test. The results show the fetus has the condition. After further consideration she changes her mind and opts for a termination.

$\mathrm{BMD}$ is an X-linked recessive condition caused by mutations in the dystrophin gene. The dysprophin protein is important for muscle function and boys with BMD will have progressive muscle weakness and wasting. There is no cure and although the condition is very variable, someone affected by the condition is likely to be wheelchair bound from adolescence onwards and life expectancy is around 40-50 years of age.

It is widely accepted that a key goal of genetic counselling when offering prenatal testing, whether offered by a genetic counsellor or other appropriately trained healthcare professional, is to support women to make informed choices regarding their pregnancies, thus allowing the exercise of reproductive autonomy. ${ }^{37,38}$ When a person acts autonomously, she exercises an informed choice free from undue influence. Autonomy is compromised (and therefore informed consent is invalidated) whenever an individual's decision is subject to coercion or illegitimate pressure. The relative ease and risk-free nature of acquiring information through NIPT has the dual opposing effect of allowing women to exercise their reproductive autonomy by removing one of the barriers (risk of miscarriage) to information, and potentially threatening autonomous decision-making if the very ease and safety of NIPT contributes to a feeling of pressure to take the test. Thus, it is important to be aware that although people, like Katie, with experience of a particular condition in their family may be informed about the condition itself, their decisions regarding prenatal testing can be influenced by the types of tests they are presented with.

There is continuing debate about whether widening the scope of prenatal testing creates further options for autonomous decisionmaking or hinders reproductive autonomy by increasing pressure to make decisions, ${ }^{39}$ and putting further responsibility upon the prospective mother. ${ }^{40}$ It has been suggested that the medical procedures for prenatal testing 'decentre parents as moral agents responsible for reproductive outcomes. ${ }^{41}$ A woman's decision about prenatal testing inevitably has heavy moral content, relating to her own wellbeing, the interests of her family, her moral obligations towards the unborn child, the message to the disabled community and the impact of her decision on society. Many women will, to greater and lesser degrees, feel the burden of these decisions. In the context of invasive testing, there is an added consideration, namely the risk of miscarriage. It is possible that, by removing the risk of miscarriage, the fundamental experience of decision-making will change significantly and women may feel undue pressure to take up NIPT. The possibility for increased pressure to take up NIPT has the potential to arise from a variety of sources, including how the information is conveyed, societal expectations and the removal of reasons (risk of miscarriage) against testing.

The possibility of increased societal pressure to test and terminate has been highlighted by health professionals, ${ }^{5}$ women using NIPT for fetal sexing ${ }^{21}$ and the public in regard to NIPT. ${ }^{6}$ In a study conducted in the United States, health professionals perceived that patients faced strong social pressures to undergo prenatal testing and claimed that additional caution may be necessary to ensure these pressures do not have undue influence on patient decision-making around testing and 
termination of pregnancy. ${ }^{5}$ Similarly, Kelly et al ${ }^{6}$ identified a concern among the general public in the UK that NIPT would promote attitudes towards 'perfection' in reproduction.

It is also possible that the very existence of NIPT will prompt feelings of pressure to make use of this new technology. The suggestion that the availability of a particular technology can create a perceived need is one that has been raised before in the context of prenatal testing. Seavilleklein ${ }^{42}$ suggests that 'the existence of the technology and the way it is portrayed creates the perception that it is a necessary part of prenatal care, not merely an optional one'. The concern is that women who do not necessarily want testing or do not want to make decisions about termination of pregnancy may have difficulty declining NIPT, which is easy to access and carries no risk to the fetus. For this reason, if reproductive autonomy is to be respected, it is critical that expert pre- and post-test counselling is provided to ensure that decision-making is in line with the parents' values and beliefs. ${ }^{43,44}$

Finally, it is important to note that for Katie, while she may not have set out to make a decision about whether to terminate the pregnancy, she was nevertheless equipped with information that helped her make a decision, which might actually have led to a better outcome for her and her family. Katie felt quite differently about her situation once she knew the diagnosis. If Katie was able to make an informed and considered decision based on that information, then arguably she was in a better position once she had the knowledge, even if she did not anticipate making this particular choice.

\section{Hypothetical scenario 3: a newly diagnosed carrier}

Litsa is pregnant with her first child and her doctor has advised her to have a number of blood tests, including routine haemoglobinopathy screening for her and her partner. At a later appointment Litsa is told that she and her partner are carriers of beta thalassaemia. Litsa is reeling from this news and when her doctor suggests that she has a blood test to diagnose the condition she immediately accepts. When the results come back they are positive and Litsa suddenly finds herself facing a decision about whether to continue the pregnancy.

Beta thalassaemia is an autosomal recessive condition caused by mutations in the $H B B$ (beta haemoglobin) gene, which is involved in the production of the oxygen-carrying molecule haemoglobin. In people affected by beta thalassaemia there is not enough normal haemoglobin and this results in severe anaemia. People with beta thalassaemia will need regular monitoring and treatment, such as blood transfusions, throughout their lives.

One of the major concerns around the introduction of NIPT for aneuploidies has been the potential for a diagnostic blood test to become routinised and undermine informed consent. ${ }^{1,4,45}$ This scenario demonstrates how these concerns might also apply in certain circumstances when offering NIPT for single gene disorders. When women newly discover they are carriers of a single gene disorder during pregnancy, they are pressed for time to make decisions about prenatal testing for a condition of which they were not previously aware they were at risk. Women who know they are carriers before conception commonly have a plan in mind about whether they will opt for prenatal testing and have time and space to think through decisions. ${ }^{20,46}$ Women whose carrier status is revealed during pregnancy, however, may be particularly vulnerable to inadvertently finding themselves on a pathway to diagnostic testing and a decision about whether to continue or terminate the pregnancy.
In these cases, the offer of a 'simple blood test' for diagnosis may undermine informed consent if women are not properly counselled.

The World Health Organisation encourage screening programmes for haemoglobin disorders. ${ }^{47}$ The National Health Service Sickle Cell and Thalassaemia Screening Programme ${ }^{11}$ was initiated in 2001 and aims to offer universal antenatal and newborn carrier screening. Research exploring parental experiences of the prenatal screening programme has highlighted difficulties in facilitating informed consent, demonstrating a clear need for parents to have better information and be better prepared for results. For example, one qualitative study found that many women did not realise they had had screening or had misunderstandings about the test. ${ }^{48}$ Another concern that has been raised about the UK prenatal carrier screening programme comes from research with general practice physicians in the UK, which found that sickle cell and thalassaemia carrier screening offered through primary care is often presented as a routine test. ${ }^{49}$ In a parallel study of women's views, women reported that general practice physicians present the test in a positive light, encouraging women to undergo screening. ${ }^{50}$ This approach was not, however, necessarily viewed negatively by the women. ${ }^{50}$ With these existing concerns around gaining informed consent and routinisation of testing already present in existing prenatal carrier screening programmes, additional caution will be required when introducing NIPT into this setting to ensure this test is not perceived as a routine next step following a positive carrier screening result.

As tests become part of routine clinical practice, they become normalised and harder to question or decline. ${ }^{51}$ Routinisation has been observed with ultrasonography whose use in prenatal care has been shown to undermine informed consent. ${ }^{52,53}$ While ultrasonography was originally intended to assess gestational age, monitor fetal development and detect fetal anomalies, it is also now viewed as having an important emotional role in pregnancy because of the fetal-maternal bonding that takes place from being able to visualise the fetus. ${ }^{54,55}$ As a result, it has been found that women have difficulty refusing it for fear of being judged irrational or irresponsible. ${ }^{51}$ Women's trust in health services and health professional opinions may also lead them to take up tests that are viewed as a standard part of prenatal care. ${ }^{56}$ In addition, women may not fully understand the purposes for which an ultrasound scan is carried out and therefore are wholly unprepared for adverse findings. ${ }^{55,57}$ The concerns here are very similar to those raised for aneuploidy screening programmes, in which the pitfalls of NIPT for aneuploidy being offered as a routine test and the resultant threat to informed consent has been discussed at length. ${ }^{45,58}$ This scenario demonstrates how this concern extends to NIPT for single gene disorders and again highlights the need for thorough counselling and consent procedures when NIPT is offered.

\section{Hypothetical scenario 4: partner refusing carrier testing}

Jasmine has known since childhood that she is a carrier of sickle cell disease. She has recently found out she is pregnant and would like her partner, Clive, to undergo carrier testing to see whether the fetus is at risk. Clive refuses carrier testing. The haemoglobinopathy nurse offers Jasmine NIPT for diagnosis.

Sickle cell disease is an autosomal recessive condition caused by a change in the $H B B$ (beta haemoglobin) gene that results in the production of an abnormal form of haemoglobin (haemoglobin S) that affects the red blood cells, sometimes altering their normal disklike shape to a sickle-shape (longer, curved and pointed). This change can cause health problems such as episodes of pain or infections. 
Although the treatment for sickle cell disease has improved in recent years, this disease is still associated with significant morbidity and reduced life expectancy.

As sickle cell disorder is an autosomal recessive condition, to be certain the pregnancy is at risk the carrier status of both parents must be known. Couples are not always in agreement about carrier testing or may not be ready to seek testing at the same time. For example, timely testing of partners when pregnant women are identified as carriers has been reported to be a major challenge for the UK Sickle Cell and Thalassaemia Screening Programme, ${ }^{59}$ where early identification of parental carrier status is seen as key to making less time-pressured decisions. In this scenario, NIPT offers Jasmine a resolution of her uncertainty that does not involve waiting for her partner to change his mind, or risking miscarriage through invasive testing.

Legally, in terms of human rights law, the ultimate decision-maker for whether to undergo any prenatal testing is Jasmine, on the basis that it is her body, her pregnancy and therefore her right to accept or decline relevant tests and information. ${ }^{60}$ In some circumstances, such as testing in conditions where diagnosis will impact on treatments administered during pregnancy, there would also be a moral case for the woman to make a decision in the best interest of her child. However, a decision to take up prenatal diagnosis is not without sacrifice; by testing without Clive's permission, Clive's privacy may be invaded if the fetus is found to be affected. This is not unusual in genetic testing, as genetic information about one person will often reveal facts about a biological relation, which gives rise to competing rights of individuals. Further, if the test results are disclosed to Clive without his permission, then this would violate his right not to know his carrier status. Ultimately, any protection of privacy may be shortlived if the pregnancy went to term, as in the UK newborns at risk of sickle cell disease are tested as knowledge of disease status can aid management to improve clinical outcomes.

Clive's right not to know ${ }^{61}$ is recognised in genetic practice, but in this case may impede on Jasmine's rights. Assuming that Jasmine has a positive right ${ }^{62}$ to NIPT under these conditions, depriving her of the test on the grounds that it would be a violation of her partner's right not to know, and an invasion of his privacy would be to put Clive's rights above hers. In Jasmine's case, the invasion of her partner's privacy could be justified on the grounds that the information sought is primarily information that belongs to her, and the results only incidentally give information about her partner. Jasmine's intention is to know whether her fetus has sickle cell; finding out about her partner's carrier status is a foreseen but unintended consequence of this. These ethical arguments apply regardless of how the diagnostic test is performed (invasive or NIPT), but in the case of NIPT where there is no risk to the pregnancy, the offer may be more appealing and more likely to be taken up.

It has been argued that the shared nature of genetic information and the moral obligations of familial relationships invites a communitarian approach, ${ }^{63}$ which would steer a compromise between the competing principles of, on the one hand, (Clive's) privacy and the right not to know, and, on the other hand, (Jasmine's) right to knowledge about her fetus. As NIPT would not necessarily reveal carrier status (if the result is negative), opting for NIPT over carrier testing may offer a compromise for respecting Clive's right not to know his carrier status as far as possible without depriving Jasmine of her right to information about her pregnancy. There may also be remaining concerns about the partner's lack of involvement (particularly if the test result is positive), and an asymmetry in the parents' level of knowledge. These are issues that should be addressed during genetic counselling.

\section{CONCLUSION}

Imagining the possible future uses of NIPT for single gene disorders is helpful in considering in advance the ethical implications for changes in practice. This is particularly important as the nature and scope of prenatal testing is rapidly changing and becoming increasingly complex. New techniques for more detailed testing such as array $\mathrm{CGH}$ and genome-wide sequencing are coming into practice and new ways of offering tests such as direct to consumer are playing a greater role. Accordingly, many of the issues described here are not unique to NIPT and will be pertinent for other areas of practice. If NIPT is expanded for use in the diagnosis of single gene disorders, policy and guidelines will have an important role to play in ensuring procedures are in place for good practice. What 'good practice' constitutes will largely be a matter for policymakers and professional bodies to decide, and this may vary between countries. We suggest that, if the wellbeing of the mother and potential child, fairness and respect for reproductive autonomy are central values driving prenatal testing, then practitioners and policymakers should continue to strive for consistent service provision, and high-quality information giving and counselling by genetic counsellors or other appropriately trained healthcare professionals who are uniquely placed to promote informed choice. ${ }^{64,65}$ Further consideration should be given to whether and how widely available NIPT should be for information only when there is no clinical benefit, and whether this should be state or privately funded, issues which are likely to vary between countries and which may largely depend on the local economic state.

\section{CONFLICT OF INTEREST}

The authors declare no conflict of interest.

\section{ACKNOWLEDGEMENTS}

This manuscript presents independent research commissioned by the National Institute for Health Research (NIHR) under the Programme Grants for Applied Research programme RP-PG-0707-10107 (the 'RAPID' project). The views expressed in this presentation are those of the authors and not necessarily those of the NHS, the NIHR or the Department of Health.

1 Newson AJ: Ethical aspects arising from non-invasive fetal diagnosis. Semin Fetal Neonatal Med 2008; 13: 103-108.

2 Benn PA, Chapman AR: Practical and ethical considerations of noninvasive prenatal diagnosis. JAMA 2009; 301: 2154-2156.

3 Hall A, Bostanci A, Wright CF: Non-invasive prenatal diagnosis using cell-free fetal DNA technology: applications and implications. Public Health Genom 2010; 13: 246-255.

4 de Jong A, Dondorp WJ, de Die-Smulders CE, Frints SG, de Wert GM: Non-invasive prenatal testing: ethical issues explored. Eur J Hum Genet 2010; 18: 272-277.

5 Sayres LC, Allyse M, Norton ME, Cho MK: Cell-free fetal DNA testing: a pilot study of obstetric healthcare provider attitudes toward clinical implementation. Prenat Diagn 2011; 31: 1070-1076

6 Kelly SE, Farrimond HR: Non-invasive preantal genetic testing: a study of public attitudes. Public Health Genom 2012; 15: 73-81.

7 Maliszewski KT: An Assessment of Genetic Counselors' Opinions on How Non-Invasive Prenatal Diagnosis may Impact Genetic Counseling Services. Waltham, MA: Brandeis University 2010 available online at https://bir.brandeis.edu/handle/10192/24065 (accessed September 2012).

8 Kooij L, Tymstra T, Berg P, Kooij L, Tymstra T: Berg Pvd: the attitude of women toward current and future possibilities of diagnostic testing in maternal blood using fetal DNA. Prenat Diagn 2009; 29: 164-168.

9 Clinical Molecular Genetics Society (CMGS): Audit 2010-2011available from. http://wwwcmgsorg/CMGS\%20audit/2011\%20audit/CMGSAudit10_11_FINALpdf (accessed March 2012).

10 Metcalfe SA: Carrier screening in preconception consultation in primary care. J Community Genet 2012; 3: 193-203. 
11 NHS Sickle Cell and Thalassaemia Standards for the Linked Antenatal and Newborn Screening Program 2011.

12 Chitty LS, Griffin DR, Meaney C et al: New aids for the non-invasive prenatal diagnosis of achondroplasia: dysmorphic features, charts of fetal size and molecular confirmation using cell-free fetal DNA in maternal plasma. Ultrasound Obstet Gynecol 2011; 37: 283-289.

13 Mujezinovic F, Alfirevic Z: Procedure-related complications of amniocentesis and chorionic villous sampling: a systematic review. Obstet Gynecol 2007; 110: 687-694.

14 Lo YM, Zhang J, Leung TN, Lau TK, Chang AM, Hjelm NM: Rapid clearance of fetal DNA from maternal plasma. Am J Hum Genet 1999; 64: 218-224.

15 Lau T, Leung T, Chan L et al: Fetal DNA clearance from maternal plasma is impaired in preeclampsia. Clin Chem 2002; 4: 2141-2146.

16 Lo YM, Tein MS, Lau TK et al: Quantitative analysis of fetal DNA in maternal plasma and serum: implications for noninvasive prenatal diagnosis. Am J Hum Genet 1998 62: 768-775.

17 Hill M, Finning K, Martin P et al: Non-invasive prenatal determination of fetal sex: translating research into clinical practice. Clin Genet 2011; 80: 68-75.

18 Lun FM, Chiu RW, Allen Chan KC, Yeung Leung T, Kin Lau T, Dennis Lo YM: Microfluidics digital PCR reveals a higher than expected fraction of fetal DNA in maternal plasma. Clin Chem 2008; 54: 1664-1672.

19 Finning KM, Chitty LS: Non-invasive fetal sex determination: impact on clinical practice. Semin Fetal Neonatal Med 2008; 13: 69-75.

20 Lewis C, Hill M, Skirton H, Chitty L: Non-invasive prenatal diagnosis for fetal sexing what is the value for service users? Eur J Hum Genet 2012; 20: 1127-1133.

21 Lewis C, Hill M, Skirton H, Chitty L: Fetal sex determination using free fetal DNA: service users' experiences and preferences for how the service should be offered in clinical practice. Prenat Diagn 2012; 32: 735-741.

22 Hill M, Taffinder S, Chitty LS, Morris S: Incremental cost of non-invasive prenatal diagnosis versus invasive prenatal diagnosis of fetal sex in England. Prenat Diagn 2011; 31: 267-273.

23 Raymond FL, Whittaker J, Jenkins L, Lench N, Chitty LS: Molecular prenatal diagnosis: the impact of modern technologies. Prenat Diagn 2010; 30: 674-681.

24 Meaney C, Norbury G: Noninvasive prenatal diagnosis of early onset primary dystonia I in maternal plasma. Prenat Diagn 2009; 29: 1218-1221.

25 Galbiati S, Brisci A, Lalatta F et al: Full COLD-PCR protocol for noninvasive prenatal diagnosis of genetic diseases. Clin Chem 2011; 57: 136-138.

26 Tsui NB, Kadir RA, Chan KC et al: Noninvasive prenatal diagnosis of hemophilia by microfluidics digital PCR analysis of maternal plasma DNA. Blood 2011; 117 3684-3691.

27 Lun FM, Tsui NB, Chan KC et al: Noninvasive prenatal diagnosis of monogenic diseases by digital size selection and relative mutation dosage on DNA in maternal plasma. Proc Natl Acad Sci USA 2008; 105: 19920-19925.

28 Barrett AN, McDonnell T, Chitty LS: Digital PCR analysis of maternal plasma for noninvasive detection of sickle cell anaemia. Clin Chem 2012; 58: 1026-1032.

29 Lo $\mathrm{Y}$, Chan $\mathrm{K}$, Sun $\mathrm{H}$ et al: Maternal plasma DNA sequencing reveals the genome-wide genetic and mutational profile of the fetus. Sci Transl Med 2010; 2: 61 ra91.

30 Bot-Robin V, Sendon S, Bourzoufi $\mathrm{K}$ et al: Maternal anxiety and pain during prenatal diagnostic techniques: a prospective study. Prenat Diagn 2012; 32 562-568.

31 Berkenstadt M, Shiloh S, Barkai G, Katznelson MB, Goldman B: Perceived personal control (PPC): a new concept in measuring outcome of genetic counseling. Am J Med Genet 1999; 82: 53-59.

32 McAllister M, Payne K, Macleod R, Nicholls S, Dian D, Davies L: Patient empowerment in clinical genetics services. J Health Psychol 2008; 13: 895-905.

33 Skirton $\mathrm{H}$ : The client's perspective of genetic counselling - a grounded theory study. J Genet Couns 2001; 10: 311-329.

34 Sapp JC, Hull SC, Duffer S et al: Ambivalence toward undergoing invasive prenatal testing: an exploration of its origins. Prenat Diagn 2010; 30: 77-82.

35 Fan HC, Gu W, Wang J, Blumenfeld YJ, El-Sayed YY, Quake SR: Non-invasive prenatal measurement of the fetal genome. Nature 2012; 487: 320-324.

36 Hill M, Compton C, Lewis C, Skirton H, Chitty LS: Determination of foetal sex in pregnancies at risk of haemophilia: a qualitative study exploring the clinical practices and attitudes of health professionals in the United Kingdom. Haemophilia 2011; 18: 575-583.

37 O'Neil O: Autonomy and Trust in Bioethics. Cambridge: Cambridge University Press, 2002.
38 Beauchamp T, Childress J: Principles of Biomedical Ethics. Oxford: Oxford University Press, 2008.

39 Press N, Browner CH: Why women say yes to prenatal diagnosis. Soc Sci Med 1997; 45: 979-989.

40 Garcia E, Timmermans DR, van Leeuwen E: Rethinking autonomy in the context of prenatal screening decision-making. Prenat Diagn 2008; 28: 115-120.

41 Kelly SE: Choosing not to choose: reproductive responses of parents of children with genetic conditions or impairments. Sociol Health IIIn 2009; 31: 81-97.

42 Seavilleklein V: Challenging the rhetoric of choice in prenatal screening. Bioethics 2009; 23: 68-77.

43 Marteau TM, Dormandy E, Michie S: A measure of informed choice. Health Expect 2001; 4: 99-108.

44 van den Berg M, Timmermans DR, Ten Kate LP, van Vugt JM, van der Wal G: Are pregnant women making informed choices about prenatal screening? Genet Med 2005; 7: 332-338.

45 van den Heuvel A, Chitty L, Dormandy E et al: Will the introduction of non-invasive prenatal diagnostic testing erode informed choices? An experimental study of health care professionals. Patient Educ Couns 2010; 78: 24-28.

46 Henneman L, Bramsen I, van der Ploeg HM, ten Kate LP: Preconception cystic fibrosis carrier couple screening: impact, understanding, and satisfaction. Genet Test 2002; 6: 195-202.

47 Modell B, Darlison M: Global epidemiology of haemoglobin disorders and derived service indicators. Bull World Health Organ 2008; 86: 480-487.

48 Locock L, Kai J: Parents' experiences of universal screening for haemoglobin disorders: implications for practice in a new genetics era. Br J Gen Pract 2008; 58: 161-168.

49 Tsianakas V, Calnan M, Atkin K, Dormandy E, Marteau TM: Offering antenatal sickle cell and thalassaemia screening to pregnant women in primary care: a qualitative study of GPs' experiences. Br J Gen Pract 2010; 60: 822-828.

50 Tsianakas V, Atkin K, Calnan MW, Dormandy E, Marteau TM: Offering antenatal sickle cell and thalassaemia screening to pregnant women in primary care: a qualitative study of women's experiences and expectations of participation. Health Expect 2012; 15: $115-125$.

51 Sherwin S: Normalizing reproductive technologies and the implications for autonomy; in: Tong R, Anderson G, Santos A (eds). Globalizing Feminist Bioethics. Boulder, CO: Westview Press, 2001; pp 96-113.

52 Favre R, Moutel G, Duchange N et al: What about informed consent in first-trimester ultrasound screening for Down syndrome? Fetal Diagn Ther 2008; 23: 173-184.

53 Nicol M: Vulnerability of first-time expectant mothers during ultrasound scans: an evaluation of the external pressures that influence the process of informed choice. Health Care Women Int 2007; 28: 525-533.

54 Rapp R: Testing Women, Testing the Fetus: The Social Impact of Amniocentesis in America. New York: Routledge, 1999.

55 Baillie C, Smith J, Hewison J, Mason G: Ultrasound screening for chromosomal abnormality: women's reactions to false positive results. Br J Health Psych 2000; 5 377-394.

56 Heyman B, Hundt G, Sandall J et al: On being at higher risk: a qualitative study of prenatal screening for chromosomal anomalies. Soc Sci Med 2006; 62: 2360-2372.

57 Garcia J, Bricker L, Henderson J et al: Women's views of pregnancy ultrasound: systematic review. Birth 2002; 29: 225-250.

58 Deans Z, Newson AJ: Should non-invasiveness change informed consent procedures for prenatal diagnosis? Health Care Anal 2011; 19: 122-132.

59 Dormandy E, Gulliford M, Bryan S et al: Effectiveness of earlier antenatal screening for sickle cell disease and thalassaemia in primary care: cluster randomised trial. BMJ 2010; 341: c5132.

60 Paton v UK 3 EHRR 4081981.

61 Chadwick R: The philosophy of the right to know and the right not to know; in: Chadwick R, Levitt M, Shickle D (eds). The Right to Know and the Right not to Know. Brookfield: Ashgate, 1997; pp 13-22.

62 Narveson J: The Libertarian Idea. Ontario: Broadview, 2001.

63 Sommerville A, English V: Genetic privacy: orthodoxy or oxymoron? J Med Ethics 1999; 25: 144-150.

64 Hodgson J, Spriggs M: A practical account of autonomy: why genetic counseling is especially well suited to the facilitation of informed autonomous decision making $J$ Genet Couns 2005; 14: 89-97.

65 Bernhardt BA, Biesecker BB, Mastromarino CL: Goals, benefits, and outcomes of genetic counseling: client and genetic counselor assessment. Am J Med Genet 2000; 94: 189-197. 